\title{
Factors Affecting Mobile Applications of Remote Security Cameras at Home and Office: An Empirical Investigation in Southern California
}

\author{
Ahmed Elmorshidy \\ Department of Management Information Systems, Gulf University for Science and Technology, \\ West Mishref, Kuwait \\ morshidy.a@gust.edu.kw
}

\begin{abstract}
This paper aims to assess and evaluate the factors affecting mobile applications used to access and control security cameras at home and office. Survey data from 397 mobile applications users from Orange County and San Bernardino County in Southern California, USA were collected to test the proposed research model and . hypotheses through structural equation modeling. This study finds that system quality, Information quality and service quality of mobile applications have positive effects on the perceived usefulness and perceived ease of use of these applications, and in their turn, they have a positive effect on actual use of mobile applications which leads to net benefit represented in increased control of users' security, increased convenience and flexibility when remotely accessing their security cameras at both home and office. The use of mobile application to access and control security cameras is growing rapidly in homes and offices; however the benefits of using such mobile applications and factors affecting their use are still unclear in the research literature. There is a lack of researches in this area which makes this study among the first to attempts to fill this gap by empirically investigating the factors affecting the use of mobile applications of home and office security cameras as well as the benefits associated with these mobile applications.
\end{abstract}

Keywords - Mobile Commerce, Mobile applications evaluations, Home and office security cameras, Information systems evaluations, Information systems security, Information systems success, technology acceptance model, Benefits of using mobile applications, Mobile applications design.

\section{Introduction}

There is a growing trend in using security cameras at both homes and offices. Several mobile applications are designed to access and control security cameras remotely. Features include live viewing, motion detection, video alerts, night vision, cloud storage and many more. However these benefits introduced to the user of those mobile applications have not yet validated by empirical studies. Also factors affecting the use of these mobile applications are not clear in research. This paper is among the first to try to fill this research gap by empirically examining the factors affecting the use of mobile applications for security cameras at home an office. Furthermore, this paper investigates the expected benefits associated with utilizing these mobile application used to access and control security cameras at home and office. The paper is concerned with answering the two following research questions:

1. What are the factors that affect mobile applications used to access remote security cameras at home and office?

2. What are the benefits associated with using mobile applications used to access remote security cameras at home or office?

The study used both the technology acceptance model (TAM) (Davis, 1989) and the information systems (IS) success model (DeLone and McLean, 2003) as theoretical frameworks and to build the study research model. Survey data from 397 mobile applications users from Orange County and San Bernardino County in Southern California, USA

Copyright (C) 2018, the Authors. Published by Atlantis Press.

This is an open access article under the CC BY-NC license (http://creativecommons.org/licenses/by-nc/4.0/). 
were collected to test the proposed research model and hypotheses through structural equation modeling.

The results and findings of this research should have important implications at both the theoretical and practice level. At the theoretical level, it will fill out a research gap by empirically investigating the factors affecting the use of mobile applications for security cameras at home and office as well as examining the benefits associated with using these mobile applications. At the practice level, the findings of this study should provide helpful insights for designers and developers of mobile applications to focus on the features that users see most beneficial when accessing and controlling their home and office security cameras. Developers of mobile application can then redesign those applications to be more tailored and responsive to users' needs and requirements.

This paper starts by reviewing literature that leads to the development of the research hypotheses pertaining to the effect of information quality, system quality, and service quality of mobile applications and how they by their turn affect perceived ease of use, perceived usefulness, attitude, behavioral intention, and actual use of these applications. The paper then discusses the research methodology including the research model and sampling. The research results and finding are then provided and analyzed. The conclusion section at the end of the paper discusses theoretical contributions, implication for practice and the limitation of the study as well as recommendations for future research.

\section{Literature Review and Hypotheses development}

\subsection{Information Quality}

Information quality of a system is defined as the quality of the content of the information systems. The more useful is the content, the more quality is the information. Budiardjo et al (2017) empirically examined the influence of knowledge management system quality on users' continuance intention to use in three companies that had implemented a knowledge management system (KMS). The study demonstrated that both system quality and information/knowledge quality influence all the factors that drive the continuance intention regarding
KMS usage, namely perceived usefulness, satisfaction, and trust. Wang and Chien-Liang (2012) empirically investigated the influences of perceived playfulness and information systems (IS) quality on mobile phone subscribers' intentions to use the service. The results confirmed that information quality, system quality, and service quality serve as important antecedents of perceived ease of use and usefulness among mobile phone subscribers. Sumida et al (2017) compared the preference of social media sites and institutional communication channels of higher education institutions by confronting elements that form perceived usefulness and user satisfaction with the system in Brazil. The study revealed that information quality has a positive effect on perceived usefulness and perceived ease of use. This discussion suggests the following hypotheses:

H1: Information quality of mobile applications of security cameras has a positive effect on perceived usefulness of these applications

H2: Information quality of mobile applications of security cameras has a positive effect on perceived ease use of these applications

\subsection{System Quality}

System quality refers to the component of the system including hardware and software that affect the functionality of the system.

AlShibly (2014) empirically investigated the effects of characteristics of electronic document management systems on their acceptance in Jordon.

The results showed that information quality and system quality have positive effects on perceived usefulness and perceived ease of use of this system.

Lee et al (2017) examined the factors influencing the behavioral intention to use food delivery applications through an extended technology acceptance model. The results showed that usergenerated information, firm-generated information, and system quality have a significant effect on perceived usefulness. In addition, system quality and design quality strongly influenced the perceived ease of use, which improved perceived usefulness. Cheng (2013) empirically examined consumer attitudes toward the use of and consumer behavioral intention to use a Radio Frequency Identification (RFID) door security system at Taipei Arena Ice Land. The results showed that system quality has a significant positive impact on perceived usefulness and perceived ease of use and information quality also has a significant 
positive impact on perceived usefulness and perceived ease of use. Tilahun and Firtz (2015) investigated antecedents of electronic medical record system implementation success in low-resource setting hospitals. Their study showed that information quality, system quality and service quality have a significant positive effect of perceived usefulness and perceived ease of use. This discussion suggests the following hypotheses:

H3: System quality of mobile applications of security cameras has a positive effect on perceived usefulness of these applications

H4: System quality of mobile applications of security cameras has a positive effect on perceived ease of these applications

\subsection{Service Quality}

Service quality refers to the necessary functions and tasks that are needed to keep the system in good condition such as maintenance, repairs, upgrades and patches.

Hsu (2015) empirically investigated backpackers' continuing usage intention of travel websites based on expectation. The study confirmed that information quality, system quality and service quality have positive effects on perceived usefulness and perceived ease of use of travelers. Choi et al. (2015) examined the effects of product attributes and service quality of transportation card solutions on service user's continuance and word-of-mouth intention. The results confirmed that the service quality of transportation card solutions has a positive effect on the users' perceived usefulness and perceived ease of use. Tai et al. (2017) investigated website quality and online trading influences on customer acceptance of securities Brokers in Taiwan. The results demonstrated that website quality positively affects perceived usefulness and perceived ease of use, both of which are key factors in predicting users' attitudes towards usage. Fernandes and Pedroso (2017) investigated the effect of self-checkout quality on customer satisfaction and re-patronage in a retail context. They found that quality of the self-checkout systems has a positive effect on the perceived usefulness and perceived ease of use of the retail customer. Ayo et al. (2017) examined the factors affecting e-banking usage based on electronic service (e-service) quality, attitude and customer satisfaction. The result reveals that perceived eservice quality has a strong influence on customer perceived usefulness as well as perceived ease of use. Te- This discussion suggests the following hypotheses:

H5: Service quality of mobile applications of security cameras has a positive effect on perceived usefulness of these applications

H6: Service quality of mobile applications of security cameras has a positive effect on perceived ease of these applications

\subsection{Perceived Ease of Use}

Perceived ease of use refers to the degree to which a person believes that using a particular system would be free of effort.

Muchran (2015) analyzed trust, perceived ease of use, perceived usefulness and experience to intention to use internet banking. The data were obtained using questionnaire given to customers. The populations were customers of BNI Bank listed as service users of Internet banking. The results showed that perceived ease of use has significant effect on perceived usefulness and perceived ease of use has significant relationship with intention to use internet banking modernized by experience. Nasri and

Mohamed (2014) empirically examined the factors influencing the intention to use Internet Banking in Tunisia. The impact of perceived usefulness, perceived ease of use, awareness, social norm, security and privacy, and computer self efficacy on intention to use Internet banking were tested through structural equation modeling. The findings proved that customer intention to use Internet banking can be affected by perceived usefulness and perceived ease of use of Internet banking. In turn, perceived usefulness can be affected by both perceived ease of use and influence social. Joo et al. (2014) conducted a study to add new variables, namely user interface, personal innovativeness, and satisfaction in learning, to Davis's technology acceptance model TAM and also examine whether learners are willing to adopt mobile learning. The study attempted to explain the structural causal relationships among user interface, personal innovativeness, perceived ease of use, usefulness, intention to use, and satisfaction in learning. The results of the structural equation modeling revealed that user interface and perceived ease of use had significant effects on perceived usefulness. Sho and Sagynov (2015) investigated the factors that affect usefulness, ease of use, trust, and 
purchase Intention in the online environment by the applying the technology acceptance model. They examined the effects of factors such as product information, price, convenience, and perceived product or service quality on perceived usefulness.

The results showed that perceived ease of use has a significant effect on perceived usefulness for the online shopper. Dong (2017) examined why do Chinese consumers use the Internet of Things (IOT) systems and if consumers' cognitive and affect experiences moderate the relationship between psychological perception factors and perceived usefulness. The research results showed that perceived psychological factors (perceived ease of use, perceived intelligence, perceived convenience and perceived privacy risk) have significant effect on the intention and behavior of IOT systems usage through perceived usefulness. Also Cognitive experience moderates the relationship between perceived ease of use and perceived usefulness. This discussion suggests the following hypothesis:

H7: Perceived ease of use of mobile applications of security cameras has a positive effect of perceived usefulness these applications

Most studies on technology acceptance showed that perceived ease of use directly influenced attitude towards use (Bruner \& Kumar 2005). Al Zubi et al. (2017) examined the direct empirical relationship between independent variables (technology, perceived usefulness, and perceived ease of use) and intention to use internet banking (IB) among 200 SMEs owners in Yemen. The results showed that technology and perceived ease of use and perceived usefulness positively influences intention to use. Cheng (2013) evaluated RFID door security system at Taipei arena. Perceived ease of use was proven to have a significant positive impact on attitudes towards use. In a study of technology adoption in government agencies, Hamner and Qazi (2009) found a statistically significant association between perceived ease of use and attitude, indicating the important role of the ease of use in the formation of users' attitudes. Bashir and Madhavaiah (2015) found PU, PEU, trust and perceived enjoyment to be significant antecedents in predicting customers' attitude towards using Internet banking. This discussion suggests the following hypothesis: Lee et al. (2017) examined the relationships between the determinants that affect customers' use of food delivery apps. Using an extended technology acceptance model, they explored consumers' experiences in purchasing delivery food through mobile apps. They found that user-generated information, firm-generated information, and system quality have a significant effect on perceived usefulness. In addition, system quality and design quality strongly influenced the perceived ease of use, which improved perceived usefulness. This discussion suggests the following hypothesis:

H8: Perceived ease of use of mobile applications of security cameras has a positive effect on attitude towards using these applications

\subsection{Perceived Usefulness}

Perceived usefulness refers to the degree to which a person believes that using a particular system would enhance his job performance

Koutromanos et al (2015) investigated factors influencing students and in-service teachers' intention to use a spatial hypermedia application, the HyperSea. Perceived usefulness was the most important predictor linking attitudes and intentions to use such applications.

In an empirical study by Sarrab at al. (2016), they examined factors driving the adoption of mobile learning tools in Omani higher education. The authors used the technology acceptance model as a theoretical framework. Results showed that PU is significantly related to the adoption of mobilelearning Chi and Tsai (2017) empirically examined the impact of critical security factors of mobile applications on technology acceptance model. With integrated perspective, they explored the influence of key factors on perceived usefulness, perceived ease of use, use attitudes and behavior intentions. Perceived usefulness was proven to positively affect use attitudes and perceived ease of use was shown to positively impact use attitudes. Erasmus et al. (2017) tested the technology acceptance model within a South African Enterprise Resource Planning user environment through a cross-sectional survey design. The results confirmed significant paths from perceived usefulness of the information system to attitudes towards using the system. Sarkar and Khare (2017) examined the impact of consumers' personality traits such as value consciousness and coupon proneness on attitude towards online shopping. A self-administered questionnaire was used to collect data and structural equation modeling was used to analyze the data. The results indicate that perceived usefulness and perceived risk influenced 
attitude towards online shopping. Value consciousness and coupon proneness significantly moderate the impact of perceived usefulness and perceived risk on attitude towards online shopping.

H9: Perceived usefulness of mobile applications of security cameras has a positive effect on attitude towards using these applications

Yadav (2016) examined the active drivers of adoption of Internet banking in Himachal Pradesh, India. The study showed that perceived usefulness positively influences the intention to adopt Internet banking. Chen and $\mathrm{Lu}$ (2016) investigated the effect of perceived usefulness for green transportation consciousness. Their research utilized the methodology of structural equation modeling to establish the theoretical implications of the empirical results. The findings indicate that green perceived usefulness has a positive effect on using intention. Moreover, the findings also indicated that the mediation effect of perceived usefulness has the strongest power to influence using intention. Lau et al (2016) examined the factors influencing purchase intention of smart phones in Hong Kong. The authors found a significant impact of $\mathrm{PU}$ on purchase intention of smart phones Ozturk (2016) tested an extended version of technology acceptance model (TAM) to examine consumers' acceptance of radio frequency identification (RFID) cashless payment systems in the hospitality industry. The study results indicated that perceived ease of use had a significant impact on perceived usefulness and both perceived ease of use and perceived usefulness were significantly associated with intention to use.This discussion suggests the following hypothesis:

H10: Perceived usefulness of mobile applications of security cameras has a positive effect on behavioral intention to use these applications

\subsection{Attitude}

In the technology acceptance model, TAM postulates that individuals can be motivated to use an information system because of the intrinsic rewards derived, like perceived usefulness, perceived ease of use and attitude towards using the system.

Elmorshdy at al (2015) investigated factors affecting live customer support chat in Kuwait. Their study found that attitude of using live support chat has a significant effect on behavioral intentions to use this system. In a empirical study, Lee et. al (2015) investigated the relationship between attitudes towards using mobile application services and customer satisfaction. Attitudes have proven to be the most significant factor for customer satisfaction and compatibility Foong and Khoo (2015) examined the influence of accounting students' attitude on their current knowledge enhancement intention and the moderating role of the learning environment on the attitude-intention relationship. Attitude was a significant predictor of students' current knowledge enhancement intention, which, in turn, positively impacts their level of current knowledge. The learning environment significantly moderates the attitude-intention relationship. An inhibiting learning environment tends to accentuate the differences in current knowledge enhancement intention between students with good attitude and those with poor attitude toward current knowledge enhancement.

Srivastava and Dewan (2015) investigated the adoption of cloud computing amongst Indian small and medium businesses through an extension of the technology acceptance model framework. Findings suggest that attitude influences intention to use cloud computing Yushkova and Feng (2017) examined the determinants of the intention to bring mobile phones for recycling. Using structural equation modeling, the study confirmed that attitude, social norms, and knowledge contribute positively and significantly to the intention to bring phones for recycling. As for three mediating effects tested, attitude mediates the relationship between knowledge and intention, as well as between social norms and intention. This discussion suggests the following hypothesis:

H11: Attitude towards using mobile applications of security cameras has a positive effect on behavioral intention to these applications.

\subsection{Behavioral Intention}

Behavioral intention is defined as a person's perceived likelihood or subjective probability that he or she will engage in a given behavior.

Alalwan et al. (2016) examined the Influence of perceived usefulness, trust and self-efficacy on Jordanian consumers' adoption of tele-banking. Statistical results showed that perceived usefulness, trust, and self-efficacy (listed in order of their influence) are all found to be significant factors predicting behavioral intention. Behavioral intention and perceived usefulness were also confirmed to have significant influence on the adoption behavior. 
Chin et al (2011) explored the antecedents of actual use for a medical e-learning system. Results showed that intention to use medical e-learning systems positively affects actual use.

Suh et al (2015) investigated purchase intentions of consumers with respect to organic food. Key influences on intention to purchase were, in descending order, consumer past experience, attitude, subjective norms, trust, and intentions. Elmorshidy et al. (2015) empirically examined factors affecting live chat customer support in Kuwait through the technology acceptance model. The results showed a significant positive impact of behavioral intention to use live customer support chat on the actual use of this online service. This discussion suggests the following hypothesis:

H12: Behavioral intention to use mobile application of security cameras has a positive effect on the actual use of these applications

\subsection{Actual Use}

Actual use of the system is the stage when the user moves from motivation and behavioral intention to actually utilize the system and explore its features and functions.

Xinli (2015) investigated the effect of using an Electronic Monitoring System (EMS) on reducing corruption in China. The findings showed that the application of EMS has a positive effect on reducing corruption which is a net benefit introduced to organizations and the society. Alshaiby (2015) empirically examined the factors affecting quality features of decision support systems, including system quality, information quality, accompanied with perceived ease of use and perceived usefulness on decision support satisfaction and net benefits. The results revealed that system quality had positive effects on both perceived usefulness and decision support satisfaction. Information quality had positive effects on decision support satisfaction; ease of use had positive effects on perceived usefulness, and decision support satisfaction positive effects on net benefits. Hassan et al (2015) measured the success of higher education centralized administration information system in an e-government context. The study revealed that the use of the e-government information systems leads to net benefits represented in the success of this system. Lwoga (2013) examined the suitability of information systems (IS) success model in the adoption of library 2.0 technologies among undergraduate students in the African context. The study revealed a strong relationship between intention to use and actual use of the library 2.0 technologies and the net benefits to students and user of the system. Tilahun and Fritz (2015) empirically examined factors influencing the implementation of Electronic Medical Record Systems (EMR) in developing countries. User satisfaction and actual use of EMR showed the strongest effect on perceived net benefit of health professionals. Rana et al. (2013) empirically evaluated the validity of Information Systems (IS) success models for the electronic government research. The results showed a positive impact of actual use of the information systems to net benefits that such a system introduces. This discussion suggests the following hypothesis:

H13: The actual use of mobile applications of security cameras has a positive effect on the net benefits introduced to user of these applications

\section{Research Methodology}

\subsection{Research Model}

The well-established information systems (IS) success model of DeLone and McLean (2003) proposes that information quality, system quality and service quality have a positive effect on interim to use the system and on user satisfaction. These later two have a positive impact of actual use of the system, which results in net benefit. The technology acceptance model of Davis 1989 suggests that perceived usefulness of the system and perceived ease of use have a positive impact on attenuate towards using the system. This attitude has a positive impact on behavioral intention to use the system, and behavioral intention as a positive impact on the actual use of the system. In our study we have combined those two well-established theoretical frameworks to arrive at our research model in figure 1 below.

Based on the detailed literature review above, we propose that information quality, system quality and service quality of mobile applications for security cameras (at home and office) will have a positive effect on both the perceived usefulness and perceived ease of use of these mobile applications. We also propose that perceived ease of use will have a positive effect on perceived usefulness of mobile 
applications Perceived usefulness will have a positive effect on both attitude and on behavioral intention to use mobile applications. Perceived ease of use will have a positive effect on attitude to use mobile applications. We also propose that attitude will have a positive effect on behavioral intention to use these applications, and behavioral intention will have a positive effect on the actual use of mobile applications. We finally propose that the actual use of mobile applications will have a positive effect on the net benefits introduced to the users in both the home and office.

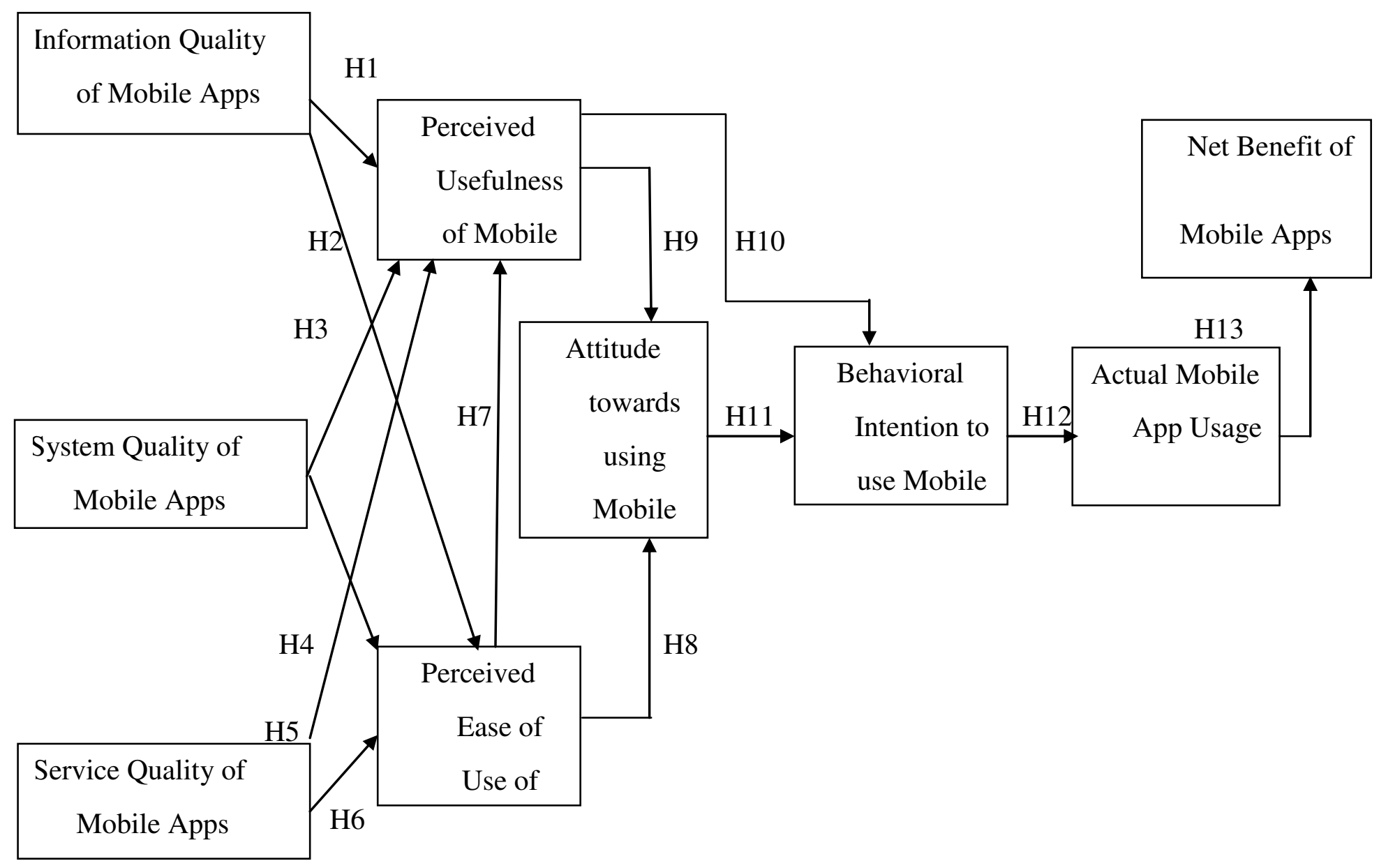

Figure 1. Research Model 


\subsection{Sampling}

The sample selected for this study was users of security cameras at home and office in both Orange County and San Bernardino County in southern California, USA. A total of 500 questionnaires were distributed in March 2018 equally between users at home and office. We emphasized the confidentiality of responses in the cover letter. Demographic information provides data regarding research participants and is necessary for the determination of whether the individuals in a particular study are a representative sample of the target population for generalization purposes.

We have received a total of 438 surveys by the deadline, 41 questionnaires were excluded because respondents did not complete the questionnaire appropriately. The final sample size was 397 , which represents a $79 \%$ response rate. The questionnaire developed to measure the variables of the study used a five-point Likert scale. The information quality, system quality and service quality and actual use constructs were adopted from DeLone and McLean (2003).

The perceived usefulness, perceived ease of use, attitude and behavioral intention constructs were adopted from Davis (1989). The first part of the questionnaire was designed to obtain some demographic information including gender, age, and type of organization that the responder belongs to. Table 1 shows the demographic profile of the respondents.

Table 1: Demographic Profile of Respondents

\begin{tabular}{llcc}
\hline Measure & Items & Frequency & Percent \\
\hline Gender & Male & 226 & 56.9 \\
& Female & 171 & 43.1 \\
& Total & 397 & 100 \\
\hline Age & $16-19$ years & 0 & 0 \\
& 19-22 years & 67 & 16.4 \\
& 22-25 years & 148 & 41.1 \\
& Above 25 years & 164 & 41.5 \\
& Total & 397 & 100 \\
\hline \multirow{2}{*}{ User at } & Home & 208 & 52.4 \\
& Office & 189 & 47.6 \\
& Total & 397 & 100 \\
\cline { 2 - 4 } & & & \\
\hline
\end{tabular}

An exploratory factor analysis (EFA) on SPSS v. 20 was carried out to explore the variables of the research model. All the proposed constructs loaded on single component. Confirmatory factor analysis was then conducted then using AMOS v.16 to assess the validity and reliability of the data. The proposed model consisted of 35 items describing eight constructs: Information quality, system quality, service quality, perceived usefulness, perceived ease of use, attitude, behavioral intention, and actual use of mobile applications of security cameras. 


\section{Research Findings and Results}

\subsection{Measurement Model}

Model testing can be carried out using measurement model if it is reliable and valid. In this case, the reliability of measures and their convergent and discriminate validity can be verified. Fornell and Larcker (1981) suggested three criteria for verifying convergent validity: the factor loading for individual items is more than 0.50 , the average variance extracted (AVE) are above 0.50 and the composite reliability (CR) of all the constructs is above 0.80. As shown in table 2 , all three criteria were met, and thus, convergent validity of the measurement model is verified. For confirmation of validity of data Cronbach Alpha is calculated and as shown in it was in all the constructs above 0.90 , which is higher than the minimum acceptable value of 0.60 as suggested by Nunnally (1978).

Table 2: Confirmatory Factor Analysis, Validity Analysis, and Reliability Test Results

\begin{tabular}{|c|c|c|c|c|c|}
\hline Concept & Item & Estimate & $\begin{array}{c}\text { Average Variance } \\
\text { Extracted } \\
(>0.50)\end{array}$ & $\begin{array}{l}\text { Composite } \\
\text { Reliability } \\
\quad(>0.80)\end{array}$ & $\begin{array}{c}\text { Cronbach Alpha } \\
\qquad(>\mathbf{0 . 6 0 )}\end{array}$ \\
\hline & IQ1 & 0.874 & & & \\
\hline & IQ2 & 0.846 & & & \\
\hline \multirow[t]{5}{*}{ Information Quality } & IQ3 & 0.851 & 0.756 & 0.947 & 0.927 \\
\hline & IQ4 & 0.834 & & & \\
\hline & IQ5 & 0.857 & & & \\
\hline & SQ1 & 0.867 & & & \\
\hline & SQ2 & 0.875 & & & \\
\hline \multirow[t]{4}{*}{ System Quality } & SQ3 & 0.828 & 0.743 & 0.948 & 0.924 \\
\hline & SQ4 & 0.819 & & & \\
\hline & SQ5 & 0.872 & & & \\
\hline & SVQ1 & 0.833 & & & \\
\hline \multirow[t]{4}{*}{ Service Quality } & SVQ2 & 0.881 & 0.716 & 0.924 & 0.913 \\
\hline & SBQ3 & 0.846 & & & \\
\hline & PU1 & 0.859 & & & \\
\hline & PU2 & 0.883 & & & \\
\hline \multirow[t]{4}{*}{ Perceived Usefulness } & PU3 & 0.878 & 0.762 & 0.941 & 0.943 \\
\hline & PU4 & 0.862 & & & \\
\hline & PU5 & 0.854 & & & \\
\hline & PEU1 & 0.861 & & & \\
\hline Perceived Ease of Use & PEU2 & 0.879 & 0.759 & 0.936 & 0.931 \\
\hline
\end{tabular}


Table 2, cont.

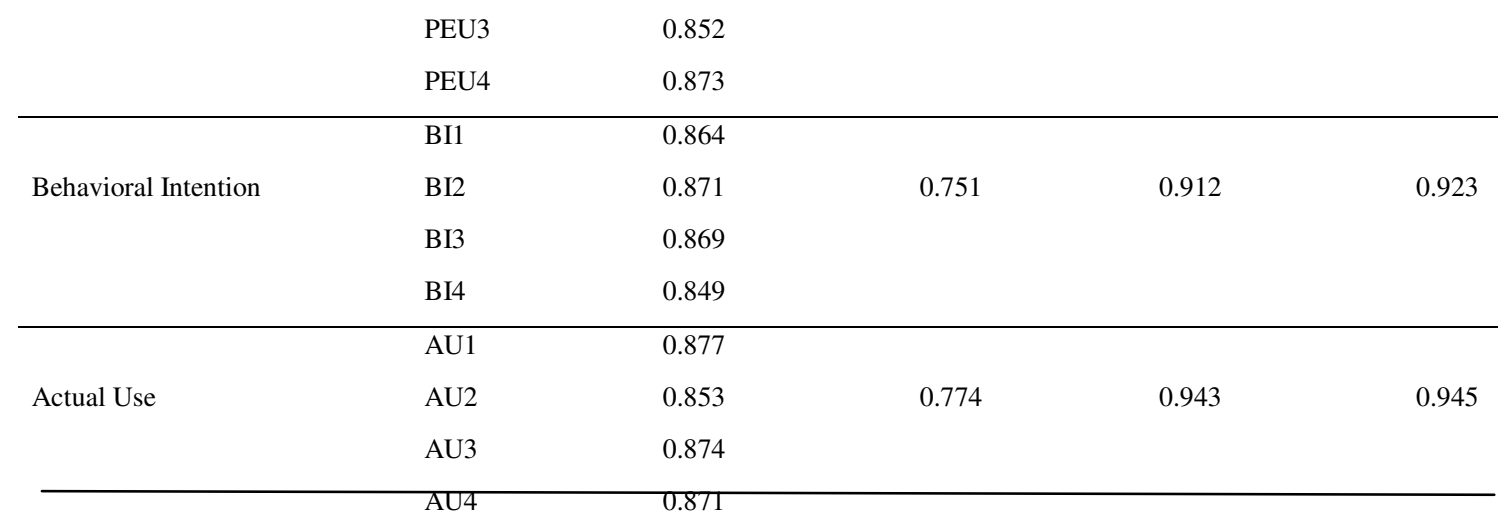

To assess the discriminate validity of the constructs, product moment correlations between the variables was conducted as shown in Table 3 below. This was to assess the associations among the eight constructs constituting the model. All the correlation coefficients were significant which show that the constructs have a high degree of relation to each others.

Table 3: Discriminate Validity of constructs (Correlation Analysis)

\begin{tabular}{|c|c|c|c|c|c|c|c|}
\hline Construct & IQ & SQ & SVQ & $\mathrm{PU}$ & $\begin{array}{ll}\text { PEU } & \text { B }\end{array}$ & I & $\overline{\mathrm{AU}}$ \\
\hline IQ & 0.859 & & & & & & \\
\hline SQ & 0.289 & 0.842 & & & & & \\
\hline SVQ & 0.342 & 0.241 & 0.848 & & & & \\
\hline PU & 0.359 & 0.354 & 0.478 & 0.863 & & & \\
\hline PEU & 0.428 & 0.289 & 0.643 & 0.411 & 0.874 & & \\
\hline BI & 0.436 & 0.307 & 0.599 & 0.298 & 0.478 & 0.853 & \\
\hline $\mathrm{AU}$ & 0.485 & 0.311 & 0.405 & 0.378 & 0.307 & 0406 & 0.877 \\
\hline
\end{tabular}

\subsection{Structural Model Analysis / Hypotheses Testing}

Structural Equation modeling was applied next to investigate the relationships among the research variables and the standardized path coefficients for confirmation of the hypotheses proposed. As shown in Table 4, the measurement model test presented a good fit between the data and proposed measurement 
Table 4: Overall Fit Measurement / Model Evaluation

\begin{tabular}{lcc}
\hline \multicolumn{1}{c}{ Measure } & Suggested Value & Observed Value \\
\hline Root mean square residual (RMR) & $<0.05$ & 0.041 \\
Comparative fit index (CFI) & $>0.9$ & 0.957 \\
Goodness of fit index (GFI) & $>0.9$ & 0.963 \\
Normed fit index (NFI) & $>0.9$ & 0.982 \\
Non-normed fit index & $>0.9$ & 0.976 \\
Root mean square error of approximation (RMSEA) & $<0.05$ & 0.373 \\
\hline
\end{tabular}

Table 5 below shows the results of the whether each hypothesis was supported or not: hypotheses testing indicating the Standard Path Coefficients, T-Values, Significance and

Table 5: Hypotheses testing results

\begin{tabular}{lllll}
\hline \multicolumn{1}{c}{ Hypothesis } & Standard Path Coefficients & & & \\
& & & & \\
& & & & \\
& & & \\
& & & \\
& & & & \\
\hline H1:IQ to PU & 0.412 & 7.731 & $\mathrm{p}<0.001$ & Yes \\
H2: QQ to PEU & 0.284 & 7.116 & $\mathrm{p}<0.001$ & Yes \\
H3: SQ to PU & 0.274 & 6.179 & $\mathrm{p}<0.001$ & Yes \\
H4: SQ to PEU & 0.313 & 8.322 & $\mathrm{p}<0.001$ & Yes \\
H5: SVQ to PU & 0.245 & 7.443 & $\mathrm{p}<0.001$ & Yes \\
H6: SVQ to PEU & 0.318 & 7.255 & $\mathrm{p}<0.001$ & Yes \\
H7: PEU to PU & 0.248 & 6.256 & $\mathrm{p}<0.001$ & Yes \\
H8: PEU to ATT & 0.311 & 7.425 & $\mathrm{p}<0.001$ & Yes \\
H9: PU to ATT & 0.294 & 8.356 & $\mathrm{p}<0.001$ & Yes \\
H10: PU to BI & 0.478 & 8.451 & $\mathrm{p}<0.001$ & Yes \\
H11: ATT to BI & 0.584 & 8.567 & $\mathrm{p}<0.001$ & Yes \\
H12: BI to AU & 0.529 & 7.561 & $\mathrm{p}<0.001$ & Yes \\
H13: AU to NI & 0.452 & $7 . .458$ & $\mathrm{p}<0.001$ & Yes \\
\hline
\end{tabular}

IQ = Information quality; SQ = System quality, SVQ = Service quality, PEU = Perceived ease of use; PU = Perceived usefulness; $\mathrm{BI}=$ Behavioral intention; ATT $=$ Attitude; $\mathrm{AU}=$ Actual use, and NI = Net benefit. 
IQ has a significant positive effect on PU $(\beta=0.412)$, and thus hypothesis $\mathrm{H} 1$ is accepted. IQ has a significant positive effect on PEU $(\beta=0.284)$, and thus hypothesis H2 is accepted. SQ has a significant positive effect on PU $(\beta=0.274)$, and thus hypothesis H3 is also accepted. SQ has a significant positive effect on PEU $(\beta=0.313)$, and thus hypothesis H4 is accepted. SVQ has a significant positive effect on PEU ( $\beta=0.245)$, and thus hypothesis H5 is accepted. SVQ has a significant positive effect on PEU ( $\beta$ $=0.318)$, and thus hypothesis $\mathrm{H6}$ is also accepted. PEU has a significant positive effect on PU $(\beta=0.248)$, and thus hypothesis $\mathrm{H7}$ is accepted. PEU has significant positive effect on ATT $(\beta=0.311)$, and thus hypothesis H8 is accepted. PU has a significant positive effect on ATT $(\beta=0.294)$, and thus hypothesis H9 is accepted. PU has a significant positive effect on BI $(\beta=0.478)$, and thus hypothesis $\mathrm{H} 10$ is accepted. ATT has a significant positive effect on BI ( $\beta=0.584)$, and thus hypothesis H1 1 is accepted. BI has a significant positive effect on $\mathrm{AU}(\beta=0.529)$, and thus hypothesis $\mathrm{H} 12$ is accepted. AU has a significant positive effect on NI $(\beta=0.452)$, and thus Hypothesis H13 is also accepted

\subsection{Discussion of Results}

The results of study assessed the factors affecting mobile applications of security cameras at home and office as well as the benefits associated with the use of these applications. It was shown that the information quality, system quality and service quality of mobile applications have a significant positive effect on perceived usefulness and perceived ease of use these applications.

This conforms to previous studies (Sumida et al., 2017; Tilahun and Firtz, 2015; Te-Tai, 2017). The results also showed that perceived ease of use of those mobile applications has a positive effect on perceived usefulness by the users, which also conforms to previous studies (Dong, 2017; Sho and Sagynov, 2015).

It was also shown that perceived ease of use of mobile applications has a significant positive effect on attitude towards using them. This further conforms to previous studies (Enayati et al., 2017; Lee et al., 2017).

The results of the study also revealed that perceived usefulness of mobile applications has a significant positive effect on attitude towards using these applications as confirmed by previous studies (Chi and Tsai, 2017; Mitzner, 2017; Erasmus et al., 2017).

It was also shown that perceived usefulness of mobile applications has a significant positive effect on behavior intention to use these applications, which matches previous studies. (Chen and Lu, 2016; Ozturk, 2016; Henderson, 2015).

The results of study further revealed that attitude towards using mobile applications has a significant positive impact on behavioral intention to use these applications, which conforms to other studies (Foong and Khoo, 2015; Perry, 2017; Yushkova and Feng, 2017).
The study also showed that behavioral intention to use mobile applications has a positive effect on the actual use of those applications, which also conforms to previous studies (Yan and Chung, 2017; Kuhlman et al, 2017; Aras et al, 2015).

Finally the results showed that actual use of mobile applications for security cameras at home and office has a significant positive effect on the net benefits introduced to the user of these applications, which conforms to previous studies (Hassan et al, 2015; Lwoga, 2013; Xinli, 2015). User of these mobile applications indicated that they have increased control of security over their homes and offices as well as increased convenience and flexibility when accessing the security cameras remotely through these applications. They indicated that this is due to the many features built into these mobile applications such as live viewing, motion alerts, sound, alerts, video history playback, and image and video sharing. This answers the second research questions pertaining to the benefits of using mobile applications to remotely access security cameras at home and office.

As far as the first question related to the factors that affect the use of mobile applications for home and office security cameras, the results revealed a significant positive effect of system quality, information quality and service quality on perceived usefulness and perceived ease of use of the application users, which by their turn affect attitude towards using these applications. Attitude also has a significant positive effect on behavioral intention to use those applications. Behavioral intention to use has a significant positive effect on actual use of mobile applications. 


\section{Conclusion}

\subsection{Theoretical Contributions}

At the theoretical level, this study filled a research gap by assessing and examining the factors that affect mobile applications used to access and control security cameras at home and office as well as the benefits associated with their use.

The study empirically examined those factors through two well-established models, the technology acceptance model (Davis, 1989) and the information systems (IS) success model (DeLone and McLean, 2003).

This empirical investigation is also among the first to explore the benefits of using such mobile applications to access and control home and office security cameras. It was unclear in the research literature if the benefits associated with using those mobile applications are validated.

The study showed that the Information Systems Success Model factors have significant effects on the perceived usefulness and perceived ease of use of the mobile applications of remote security cameras. The users saw that the system quality, information quality as well as service qualities of those mobile applications are very important determinates of their perceived usefulness and perceived ease of use.

Perceived usefulness and perceived ease of use also have positive influence on attitude towards using these mobile applications. Users indicated that their attitude is positively affected by the perceived usefulness and perceived ease of use of the mobile applications.

Attitude towards using mobile applications also had a positive effect on users behavioral intention to use those applications. Behavioral intention has a positive influence on actual use of mobile applications as also indicated by users. Users have further indicated that the actual use of the mobile application has positively affected the net benefits inducted to them represented in increased control of users' security, increased convenience and flexibility when remotely accessing their security cameras at both home and office. Features like live viewing, motion detection, video alerts, night vision, and cloud storage were very beneficial as indicated by the users.

\subsection{Implication for Practice}

As the practice level, the findings of this study explored and analyzed the factors that affect mobile applications of security cameras at home and office.

The benefits of using these mobile applications were also examined. The findings of this study should be helpful for the designers and develops of mobile applications to focus on the success factors that will make their applications more tailored around users' needs and requirements focusing on the features that users want to see in these applications. These features should give users more convenience and control over their home and office security cameras. The study also shows a positive relationship between usefulness, ease of use and attitude towards using mobile applications.

Developers of mobile applications should also take these guidelines in consideration when designing a responsive mobile application for security cameras.

\subsection{Limitations and Future Research}

Our study has a number of limitations. First, the study is limited in terms of the sample size and selection. The study focused on user of mobile applications in Orange County and San Bernardino County in Southern California only.

To increase the external validity of the study, it is highly recommend applying it again to other mobile applications users in other parts of world.

The second limitation is that this study used cross-sectional data rather than longitudinal data. This means it focused more on observing respondents' behaviors rather than changes in behavior. Therefore, further research is encouraged to use longitudinal data to further explain the relationship between the variables of the study. Finally, this study used a quantitative approach to examine the effect of using mobile applications for security cameras on the benefits introduced to the users at home and office.

Using both quantitative and qualitative approaches will strengthen the analysis of the relationship between variables, and will provide enhanced better results that can prove the findings of this study. 


\section{References}

1. Alalwan, A. A., Dwivedi, Y. K, Rana, N. P, Simintiras, A. C. (2016), "Jordanian consumers' adoption of telebanking: Influence of perceived usefulness, trust and self-efficacy", The International Journal of Bank Marketing; Bradford Vol. 34, No. 5, pp 690-709.

2. AlShaibly, H. H. (2014), "The effects of characteristics of electronic document management systems on their acceptance: An empirical study in Jordan", International Journal of Information, Business and Management; Chung-Li Vol. 6, No. 4, pp126-145.

3. Aras, M., and Özdemir, Y. B. (2015), "The Investigation of Perceptions for Human Resource Information Systems via Technology Acceptance Model”, Ege Akademik Bakis; Izmir Vol 15, No. 3 , pp 343-351

4. Ayo, C., Oni, A. A., Oyerinde J., Eweoya, I. O. (2016), "E-banking users' behaviour: e-service quality, attitude, and customer satisfaction", The International Journal of Bank Marketing; Bradford Vol. 34, No. 3, pp 347-367.

5. Bashir, I and Madhavaiah, C. (2015), "Consumer attitude and behavioral intention towards Internet banking adoption in India", Journal of Indian Business Research, 7, 102-67.

6. Budiardjo, F, Pamenan, G, Achmad, H, Confriyant, E (2017), "The impact of knowledge management system quality on the usage continuity and recommendation intention", Knowledge Management \& E-Learning; Hong Kong Vol. 9, Iss. 2, (2017): 200.

7. Bruner, G and Kumar, A (2005), "Explaining consumer acceptance of handheld Internet devices", Journal of Business Research, 58, 553558.

8. Chen, S. and Lu, C. (2016), "Exploring the Relationships of Green Perceived Value, the Diffusion of Innovations, and the Technology Acceptance Model of Green Transportation", Transportation Journal; Lock Haven, Vol. 55, No. 1, pp 51.

9. Chen, X., Li, S. (2017), "Understanding Continuance Intention of Mobile Payment Services: An Empirical Study", The Journal of Computer Information Systems;

Stillwater Vol. 57, No. 4, pp 287-298
10. Cheng, K. (2013), “An Evaluation of RFID Door Security System At Taipei Arena Ice Land Based On Technology Acceptance Model", International Journal of Management \& Information Systems (Online); Littleton Vol. 17, No. 2, pp 117.

11. Choi, M., Han, K., Choi, J. (2015), "The effects of product attributes and service quality of transportation card solutions on service user's continuance and word-of-mouth intention", Service Business; Heidelberg Vol. 9, No. 3, pp 463-490.

12. Chin, L. P., Ahmad, Z. A. (2015), "Consumers' Intention to Use a Single Platform E-Payment System: A Study among Malaysian Internet and Mobile Banking Users", Journal of Internet Banking and Commerce; Ottawa Vol. 20, No. 1, pp 1-13.

13. Chin, W., Lin, Y., Chiu, Y. (2011), "The Study of Antecedents of Actual Use for E-learning System, From Technical Perspective", Sansia, 8, 331-350.

14. DeLone W., and McLean E. (2003)," Information Systems Success Revisited", Proceedings of the 35th Hawaiian International Conference on Systems Sciences (HICSS-35'02). Hawaii, USA, 2002, pp $2966-2976$.

15. Davis, F.D. (1989), "Perceived usefulness, perceived ease of use, and user acceptance of information technology", MIS Quarterly, Vol.13, No. 3, pp318-39.

16. Dong, X., Chang, Y. W., Y., Yan, J. (2017), "Understanding usage of Internet of Things (IOT) systems in China: Cognitive experience and affect experience as moderator", Information Technology \& People; West Linn Vol. 30, No. 1, pp 117-138.

17. Elmorshidy, A, Moustafa, M., Moughrabi, I., Al Mezen, H. (2015), "Factors Influencing Live Customer Support Chat Service: An Empirical Investigation in Kuwait" The Journal of Theoretical and Applied Electronic Commerce Research Vol. 10, No. 3, pp. 63-76.

18. Enayati Shiraz, M. A., Ramezani, E. (2016), Impact of effective organizational characteristics on adoption of customer relationship management in Melli Bank branches in Khuzestsn province-Iran", Arabian Journal of 
Business and Management Review (Oman Chapter); Sohar Vol. 5, No. 6, pp 20-27.

19. Erasmus, E., Rothmann, S., Van Eeden, C. (2015), "A structural model of technology acceptance", SA Journal of Industrial Psychology; Auckland Park Vol. 41, No. 1, pp 112.

20. Fernandes, T., Pedroso, R. (2017), "The effect of self-checkout quality on customer satisfaction and repatronage in a retail context", Service Business; Heidelberg Vol. 11, No. 1, pp 69-92.

21. Foong, S., Khoo, C. (2015), “Attitude, learning environment and current knowledge enhancement of accounting students in Malaysia", Journal of Accounting in Emerging Economies; Bingley Vol. 5, No. 2, pp 202-221.

22. Fornell, C., and Larcker, D. F. (1981), "Evaluating structural equation models with unobservable variables and measurement error", Journal of Marketing Research, Vol. 18, No. 1, pp 39-50.

23. Hamner, M and Qazi, R (2009), "Expanding the Technology Acceptance Model to Include Additional Factors such as Personal Utility", Government Information Quarterly, Vol 26 pp. 128-136.

24. Hassan, N. S., Seyal, A. H. (2015), "Measuring Success of Higher Education Centralised Administration Information System: An eGovernment Initiative", European Conference on e-Government; Kidmore . 455-464, pp 455-464.

25. Henderson, D. L., Bradford, M., Kotb, A. (2016), "Inhibitors and Enablers of GAS Usage: Testing the Dual Factor Theory, Journal of Information Systems; Sarasota Vol. 30, No. 3, pp135.

26. Hsu, L., Chen, C., Lin, T. (2015), “““An empirical study of backpackers' continuing usage intention of travel website: Based on expectationconfirmation theory", Commerce \& Management Quarterly; Taipei Vol. 16, No. 1, pp 47-88.

27. Joo, Y. J., Lee, H. W, Ham, Y. (2014), "Integrating user interface and personal innovativeness into the TAM for mobile learning in Cyber University", Journal of Computing in Higher Education; Dordrecht Vol. 26, No. 2, pp 143-158.

28. Koutromanos, G.,Styliaras, G., Christodoulou, S. (2015), 'Student and in-service teachers' acceptance of spatial hypermedia in their teaching: The case of HyperSea", Education and Information Technologies, Vo. 20, pp 559.
29. Kuhlman, S. T., Walch, S. E., Bauer, K. N., Glenn, A.D. (2017), "Intention to Enact and Enactment of Gatekeeper Behaviors for Suicide Prevention: an Application of the Theory of Planned Behavior", Prevention Science; New York Vol. 18, No. 6, pp 704-715.

30. Lau, M., Lam, A., Cheung, R. (2016), "Examining the Factors Influencing Purchase Intention of SmartPhones in Hong Kong", Contemporary Management Research, 12, 213224.

31. Lee, C., Tsao, C., Chang, W. (2015), "The relationship between attitude toward using and customer satisfaction with mobile application services: An empirical study from the life insurance industry", Journal of Enterprise Information Management, 28, 680-697.

32. Lee, E., Lee, S., Jeon, Y. J. (2017), "Factors influencing the behavioral intention to use food delivery Apps", Social Behavior and Personality; Palmerston North Vol. 45, No. 9, pp 1461-1473.

33. Lwoga, E (2014), "Critical success factors for adoption of web-based learning management systems in Tanzania", International Journal of Education and Development using Information and Communication Technology;

Bridgetown Vol. 10, Iss. 1, (Apr/May 2014): 421.

34. Mitzner, T. L., Rogers, W. A., Fisk, A. D., Boot, W. R., Charness, N. et al, (2016), "Predicting older adults' perceptions about a computer system designed for seniors", Universal Access in the Information Society; Heidelberg Vol. 15, No. 2, pp 271-280.

35. Muchran, M. (2015), “Acceptance of banking information technology in PT BNI of Makassar", Journal of economics and behavioral studies, Vol. 7, No. 2, pp 124-130.

36. Nunnally, J. (1978). Psychometric Theory (2nd Ed.), New York: McGraw-Hill.

37. Ozturk, A. B. (2016), "Customer acceptance of cashless payment systems in the hospitality industry", International Journal of Contemporary Hospitality Management; Bradford Vol. 28, No. 4, pp 801-817.

38. Perry, A. (2017) "Factors comprehensively influencing acceptance of 3D-printed apparel", Journal of Fashion Marketing and Management; Bradford Vol. 21, No. 2, pp 219-234.

39. Rana, N. P, Dwivedi, Y. K., Williams, M. D. (2013), "Valuating the Validity of IS Success 
Models for the Electronic Government Research: An Empirical Test and Integrated Model”, International Journal of Electronic Government Research; Hershey Vol 9, No. 3, pp 1.

40. Srivastava, V. and Dewan, S. (2015), "Adoption of Cloud Computing Amongst Indian SMBs: An Extension of TAM Framework", Journal of Entrepreneurship and Management, 4, 21-27.

41. Suh, B., Eves, A., Lumbers, M. (2015), "Developing a Model of Organic Food Choices Behavior," Social Behavior and Personality, 4, 217-230.

42. Sumida G. L., Costa Silva, C. M. (2017), "Differences between perceived usefulness of social media and institutional channels by undergraduate students", Interactive Technology and Smart Education; Bingley Vol. 14, No. 3, pp 196-215.

43. Te-Tai, F., Tien, C., Zhi-Yuan, F., Lai, P.(2014), "Web Site Quality and Online Trading Influences on Customer Acceptance of Securities Brokers", Asia Pacific Management Review; Tainan Vol. 19, No. 1, pp 25-45.

44. Tilahun, B., Fritz, F. (2015), "Modeling antecedents of electronic medical record system implementation success in low-resource setting hospitals", BMC Medical Informatics and Decision Making; London Vol 15, pp 1-9.

45. Xinli, H. (2015), "Effectiveness of information technology in reducing corruption in China: A validation of the DeLone and McLean information systems success model", The Electronic Library; Oxford Vol. 33, No. 1, pp 5264.

46. Yadav, P. (2016), "Active drivers of adoption of internet banking", Independent Journal of Management \& Production, 7, 445-464.

47. Yushkova, E., Feng, Y. (2017), "What explains the intention to bring mobile phones for recycling? A study on university students in China and Germany" International Economics and Economic Policy;

48. Wang and Chien-Liang (2012), "The adoption of mobile value-added services", Managing Service Quality; Bedford Vol. 22, Iss. 2, (2012): 184208. 


\section{Appendix A: Survey Questionnaire}

Dear Participant:

The following survey is about the factors that affect mobile applications used to access security cameras at home and office and the benefits associated with using these applications.

We ask you to please indicate your perception about those factors and benefits of mobile applications through a scale of 1 to 5 (1: strongly disagree; 5 : strongly agree). Thank you.

\begin{tabular}{|c|c|c|c|c|c|c|}
\hline & Statement & $\begin{array}{l}\text { Strongly } \\
\text { Disagree }\end{array}$ & Disagree & Neutral & Agree & $\begin{array}{l}\text { Strongly } \\
\text { Agree }\end{array}$ \\
\hline 1 & $\begin{array}{l}\text { Mobile application of security cameras } \\
\text { are adaptable to my needs at home and } \\
\text { office }\end{array}$ & & & & & \\
\hline 2 & $\begin{array}{l}\text { Mobile applications of security } \\
\text { cameras are always available for me } \\
\text { when I need them }\end{array}$ & & & & & \\
\hline 3 & $\begin{array}{l}\text { Mobile applications of security } \\
\text { cameras are reliable and I can depend } \\
\text { on them at home and office }\end{array}$ & & & & & \\
\hline 4 & $\begin{array}{l}\text { Mobile applications are fast and } \\
\text { provide instant access to my security } \\
\text { cameras at home and office }\end{array}$ & & & & & \\
\hline 5 & $\begin{array}{l}\text { Mobile applications of security } \\
\text { cameras are easy to use }\end{array}$ & & & & & \\
\hline 6 & $\begin{array}{l}\text { The features provided by mobile } \\
\text { applications of security cameras are } \\
\text { adequate for my needs at home and } \\
\text { office }\end{array}$ & & & & & \\
\hline 7 & $\begin{array}{l}\text { The features provided by mobile } \\
\text { applications of security cameras are } \\
\text { user friendly and easy to understand }\end{array}$ & & & & & \\
\hline 8 & $\begin{array}{l}\text { Mobile applications provide relevant } \\
\text { features necessary to manage my } \\
\text { security cameras at home and office }\end{array}$ & & & & & \\
\hline 0 & $\begin{array}{l}\text { Mobile applications of security } \\
\text { cameras are secure and safe to use }\end{array}$ & & & & & \\
\hline 10 & $\begin{array}{l}\text { Mobile applications assure continuous } \\
\text { and uninterrupted service quality }\end{array}$ & & & & & \\
\hline 11 & $\begin{array}{l}\text { The technical support staff of mobile } \\
\text { applications are knowledgeable to } \\
\text { solve any problems that might arise }\end{array}$ & & & & & \\
\hline 12 & $\begin{array}{l}\text { The technical support staff of mobile } \\
\text { applications are responsive to my } \\
\text { questions and concerns }\end{array}$ & & & & & \\
\hline 13 & $\begin{array}{l}\text { I think it is useful to use mobile } \\
\text { applications to access my security }\end{array}$ & & & & & \\
\hline
\end{tabular}




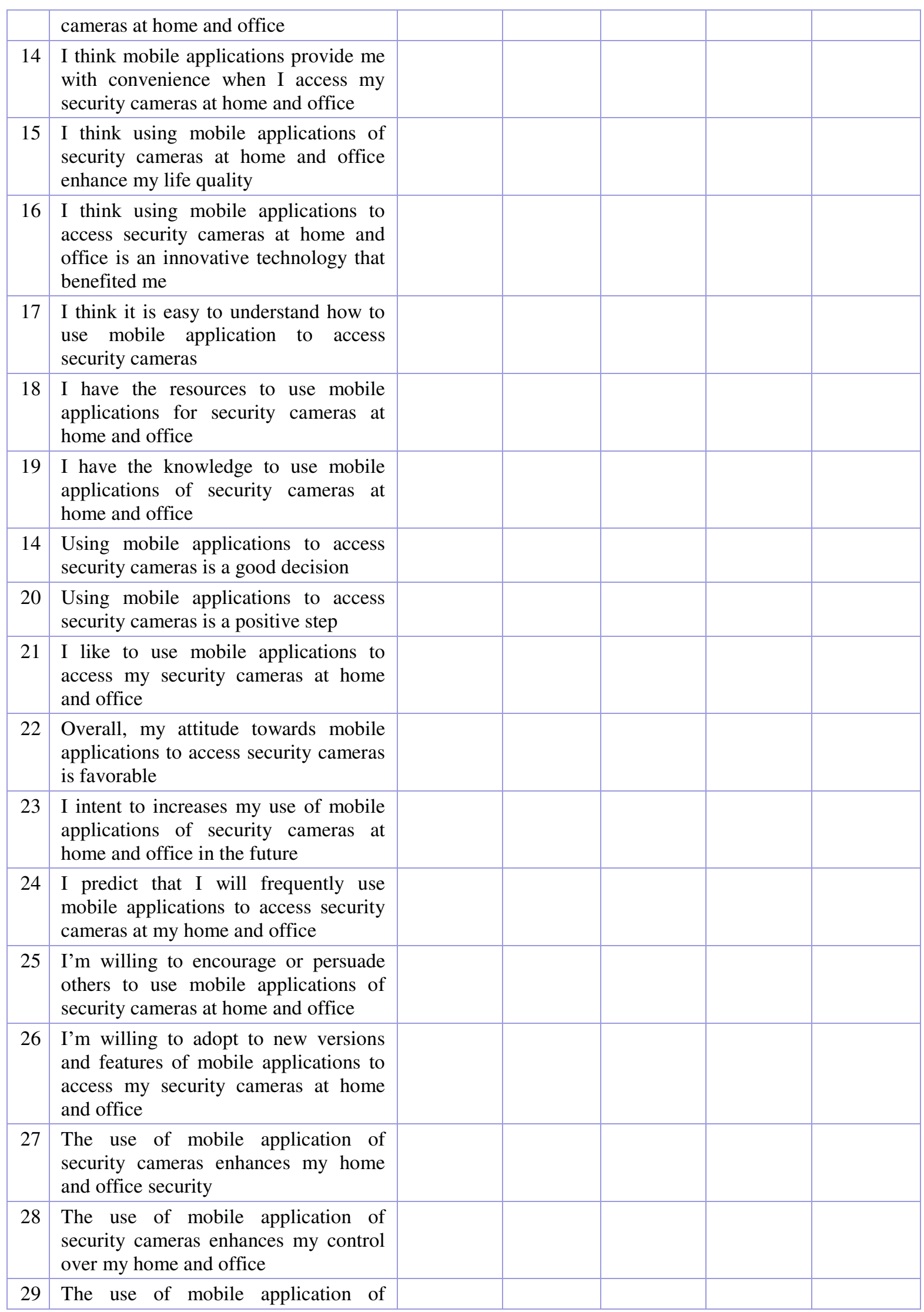




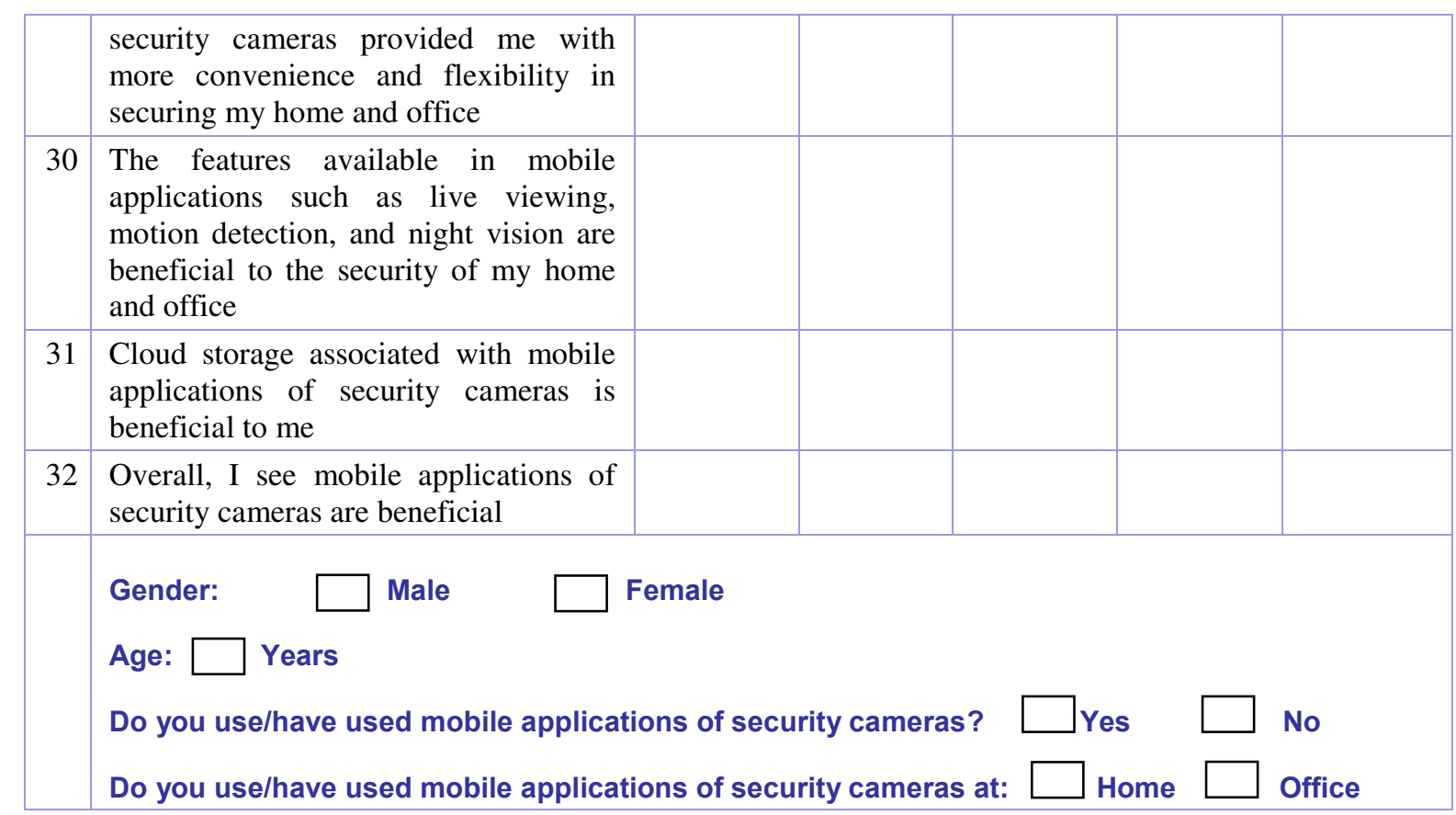

